\title{
A Four-carpeled Fruit Mutant in Jojoba
}

\author{
A. Estilai and A. Hashemi \\ Department of Botany and Plant Sciences, University of California, Riverside, \\ CA 92521-0124
}

Additional index words. Simmondsia chinensis, wax esters, unisexual, seeds per fruit, dioecious, monoecious

\begin{abstract}
Typical female jojoba [Simmondsia chinensis (Link) Schneider] plants produce three-carpeled fruit that contain one to three seeds. Examination of $\approx 13,000$ plants in a nursery at the Univ. of California, Riverside, revealed one mutant plant whose distillate flowers had four stigmas and four-carpeled fruit. The mutant plant had $42 \%$ one-seeded, $39 \%$ two-seeded, and $19 \%$ three-seeded fruit. In contrast, wild-type sibling plants averaged $83 \%$ one-seeded, $16 \%$ two-seeded, and $1 \%$ three-seeded fruit. The additional carpel in these fruit did not result in production of four seeds per fruit, but drastically altered the frequency of one-, two-, and three-seeded fruit in the mutant plant. This fruit character may serve as a useful genetic marker and, since about one-fifth of the fruit produce three seeds, it maybe useful in studies of multipaternal effects on seed development and seed-oil quality and quantity.
\end{abstract}

Jojoba is an evergreen, woody shrub native to the Sonoran Desert, Mojave Desert, and semiarid coastal scrub communities of Baja California. It is one of several potential industrial crops to reach commercial production in recent years. At present, more than 16,000 ha of jojoba are under cultivation in the United States, and sizable areas also are cultivated in Australia, India, Israel, Mexico, and South America (Prinsen, 1990). Seed oil of jojoba is unique in the plant kingdom and consists almost exclusively of liquid wax esters (Wisniak, 1987). The liquid wax is often promoted as a substitute for sperm whale oil, but it has features that make it superior in some applications (Kleiman, 1990). The current use of jojoba oil is centered in the cosmetics and personal care industries.

To our knowledge, there are no genetic studies of botanical and agronomic traits in jojoba. The long period (3-6 years) required to reach the reproductive stage has discouraged genetic investigation in this crop. However, several correlation studies were conducted to determine the relationships between botanical and agronomic traits, seed yield, and seed oil quantity (Naqvi et al., 1990; Yermanos, 1977a, 1977b).

With the exception of one monoecious individual found in Arizona, jojoba is a unisexual, dioecious, and cross-pollinating species over its entire area of natural distribution (Yermanos, 1981). Its pistillate flowers are apetalous with five unequal sepals that increase in size as fruit develop. The three-celled superior ovary ends in three stigmas. The fruit are smooth cylindrical capsules, somewhat resembling acorns (Cronquist, 1981). Each

\footnotetext{
Received for publication 21 Sept. 1992. Accepted for publication 16 Feb. 1993. The cost of publishing this paper was defrayed in part by the payment of page charges. Under postal regulations, this paper therefore must be hereby marked advertisement solely to indicate this fact.
}

About 13,000 plants growing in a 6-ha nursery at the Moreno Farm, Univ. of Califor- fruit consists of three carpels and has the potential to produce up to three seeds. We report a jojoba plant with a four-carpeled gynoecium and compare the number of seeds per fruit in this atypical plant with typical wildtype plants from several jojoba selections. We refer to the atypical plant as a mutant. nia, Riverside, were examined in this study. This plantation was established during 197378 by D.M. Yermanos, who used open-pollinated seed from at least 160 selections found in natural populations and botanic gardens. Most plants are arranged in 210-m-long rows with interrow and interplant spacings of 3 and $1.5 \mathrm{~m}$, respectively.

The gynoecia of wild-type, female plants each have three carpels, while the only mutant plant found in the field has four (Fig. 1). Parallel to the increase in carpels, the stigmas also increased from three in wild-type plants to four in the mutant. The sepals grow away from the fruit in wild-type plants but cover the fruit in the mutant.

To determine if the wild-type plants also produced four-carpeled fruit, we compared 500 fruit from five randomly chosen plants with 300 fruit from the mutant plant. Fourcarpeled fruit were rare on wild-type plants. The five plants studied ranged from 0 to $3 \%$ four-carpeled fruit per plant (mean $=1.2 \%$ and $\mathrm{SD}=1.3 \%$ ). In contrast, $98 \%$ of fruit on the mutant plant had four carpels.

The effect of an additional carpel on the number of seeds per fruit was examined by comparing seeds per fruit in five jojoba selections and in the mutant. Three plants were chosen randomly within each selection. We collected 100 fruit from each plant and recorded the number of seeds per fruit. A total of 300 fruit from the mutant plant was used to determine seeds per fruit. The percentage of fruit with one, two, or three seeds varied among

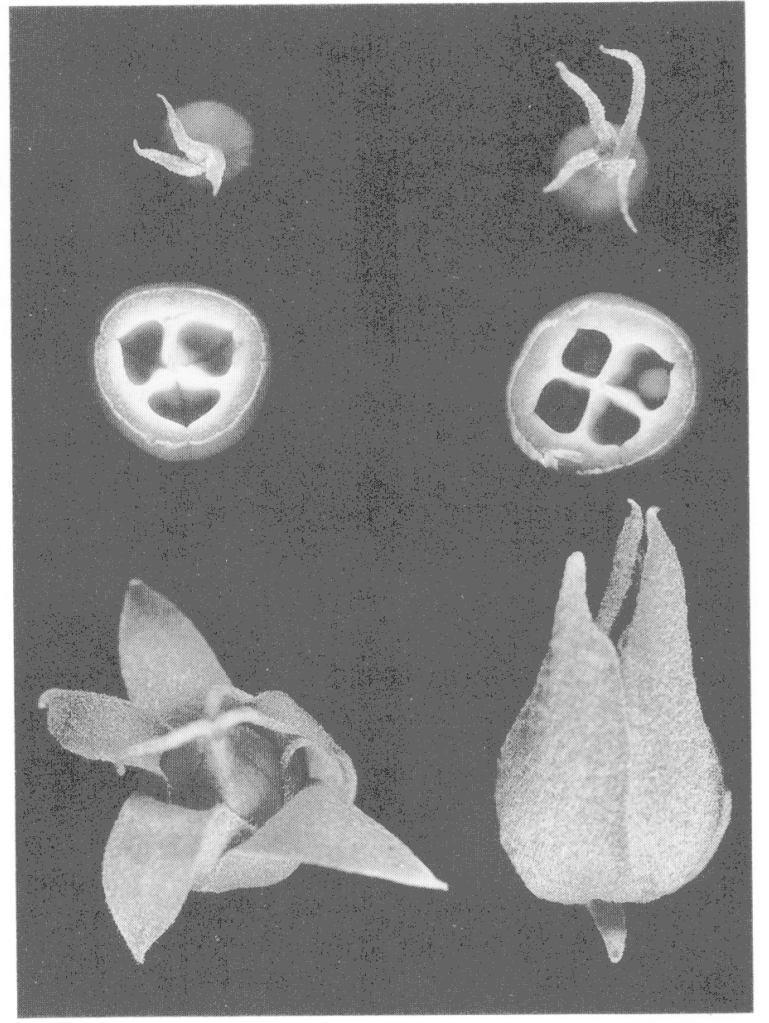

Fig. 1. (left) Three- and (right) four-carpeled fruit. Sepals were removed to show stigmas (top row), fruit cross-section (center), and whole fruit with sepals growing outward in the wild type (left) and covering the fruit in the mutant (bottom row). 
Table 1. Mean percentage of one-, two-, and three-seeded fruit in the mutant jojoba plant and five selections.

\begin{tabular}{lccc}
\hline & \multicolumn{3}{c}{ Fruit with (mean \%) } \\
\cline { 2 - 4 } Selections & One seed & Two seeds & Three seeds \\
\hline Mutant plant & 41.7 & 39.0 & 19.3 \\
Aguanga-145 & 82.6 & 16.3 & 1.1 \\
Aguanga-1 & 89.7 & 10.3 & 0 \\
Del Mar-4 & 56.7 & 38.0 & 4.6 \\
Vista & 66.6 & 29.0 & 3.7 \\
Riverside-3 & 92.7 & 7.3 & 0 \\
\hline
\end{tabular}

selections (Table 1) and from plant to plant within selections. The within-selection variation may have originated from cross-pollinated seed and, thus, these selections do not represent true clones that are commonly propagated by stem cuttings. With one exception, these jojoba plants produced predominantly one-seeded fruit (Table 1). The exception was one plant in selection Del Mar-4, which produced $38 \%$ one-seeded, $56 \%$ two-seeded, and $6 \%$ three-seeded fruit. The mean of two-seeded fruit for the five selections varied from $7.3 \%$ to $38 \%$ (Table 1). The mutant produced $39 \%$ two-seeded fruit. Selections averaged $0 \%$ (Aguanga-1 and Riverside-3) to 4.6\% (Del Mar-4) three-seeded fruit. In contrast, $19.3 \%$ of the mutant's fruit had three seeds. None of the 300 fruit from the mutant had four seeds.

The presence of an additional carpel did not result in four-seeded fruit, but it drastically changed the frequency of one-, two-, and threeseeded fruit in the mutant. The mutant pro- duced higher percentages of two- and threeseeded fruit at the expense of one-seeded fruit. This difference is especially evident when the mutant is compared to Aguanga-145, the selection in which the mutant was found. The percentage of one-seeded fruit produced by the mutant is almost half that found in the wildtype sibling plants (Table 1). In contrast, the percentage of two-seeded fruit is more than double, and the percentage of three-seeded fruit is almost 19-fold that of the wild type.

The mutant plant's production of predominantly four-carpeled fruit in two subsequent years indicates strongly that the observed gynoecium mutant is genetically controlled. To elucidate the genetic basis of this variation, controlled crosses between the mutant plant and different wild-type jojoba plants and analyses of the progeny are required, which may take more than 10 years. In the interim, cuttings from the mutant can be used to ascertain that the mutant phenotype expresses itself regularly following asexual propagation, The significance of this mutant in jojoba improvement remains to be ascertained. It may serve as a useful and easily recognizable marker. Since about one-fifth of the fruit on the mutant plant produce three seeds, the mutant may also be used to study multipaternal effects on seed development and seed oil quantity and quality.

\section{Literature Cited}

Cronquist, A. 1981. An integrated system of classification of flowering plants. Columbia Univ Press, New York.

Kleiman, R. 1990. Chemistry of new industrial oilseed crops, p. 196-203. In: J. Janick and J.E. Simon (eds.). Advances in new crops. Timber Press, Portland, Ore.

Naqvi, H.H., M. Matsumura, and I.P. Ting. 1990. Variability in seed characteristics of unselected and selected jojoba populations. HortScience 25:364.

Prinsen, L.H. 1990. New crops research and development: A federal perspective, p. 17-20. In: J. Janick and J.E. Simon (eds.). Advances in new crops. Timber Press, Portland, Ore.

Wisniak, J. 1987. The chemistry and technology of jojoba oil. Amer. Oil Chem. Soc., Champaign, Ill.

Yermanos, D.M. 1977a. Jojoba-Genetically controlled botanical traits. J. Amer. Oil Chem. Soc. 54:545-548

Yermanos, D.M. 1977b. Jojoba-A crop whose time has come. Calif. Agr. 33:4-11.

Yermanos, D.M. 1981. Monoecious jojoba. J. Amer. Oil Chem. Soc. 58:247-253. 